NASA/TM-2000-210479

\title{
Computation of Feedback Aeroacoustic System by the CE/SE Method
}

Ching Y. Loh and Xiao Y. Wang

Taitech Inc., Cleveland, Ohio

Sin-Chung Chang and Philip C.E. Jorgenson

Glenn Research Center, Cleveland, Ohio 
Since its founding, NASA has been dedicated to the advancement of aeronautics and space science. The NASA Scientific and Technical Information (STI) Program Office plays a key part in helping NASA maintain this important role.

The NASA STI Program Office is operated by Langley Research Center, the Lead Center for NASA's scientific and technical information. The NASA STI Program Office provides access to the NASA STI Database, the largest collection of aeronautical and space science STI in the world. The Program Office is also NASA's institutional mechanism for disseminating the results of its research and development activities. These results are published by NASA in the NASA STI Report Series, which includes the following report types:

- TECHNICAL PUBLICATION. Reports of completed research or a major significant phase of research that present the results of NASA programs and include extensive data or theoretical analysis. Includes compilations of significant scientific and technical data and information deemed to be of continuing reference value. NASA's counterpart of peerreviewed formal professional papers but has less stringent limitations on manuscript length and extent of graphic presentations.

- TECHNICAL MEMORANDUM. Scientific and technical findings that are preliminary or of specialized interest, e.g., quick release reports, working papers, and bibliographies that contain minimal annotation. Does not contain extensive analysis.

- CONTRACTOR REPORT. Scientific and technical findings by NASA-sponsored contractors and grantees.
- CONFERENCE PUBLICATION. Collected papers from scientific and technical conferences, symposia, seminars, or other meetings sponsored or cosponsored by NASA.

- SPECIAL PUBLICATION. Scientific, technical, or historical information from NASA programs, projects, and missions, often concerned with subjects having substantial public interest.

- TECHNICAL TRANSLATION. Englishlanguage translations of foreign scientific and technical material pertinent to NASA's mission.

Specialized services that complement the STI Program Office's diverse offerings include creating custom thesauri, building customized data bases, organizing and publishing research results ... even providing videos.

For more information about the NASA STI Program Office, see the following:

- Access the NASA STI Program Home Page at $h$ ttp://www.sti.nasa.gov

- E-mail your question via the Internet to help@sti.nasa.gov

- Fax your question to the NASA Access Help Desk at (301) 621-0134

- Telephone the NASA Access Help Desk at (301) 621-0390

- Write to: NASA Access Help Desk NASA Center for AeroSpace Information 7121 Standard Drive Hanover, MD 21076 
NASA/TM-2000-210479

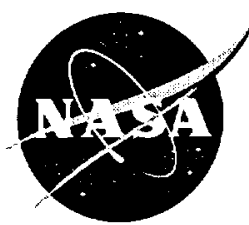

\section{Computation of Feedback Aeroacoustic System by the CE/SE Method}

Ching Y. Loh and Xiao Y. Wang

Taitech Inc., Cleveland, Ohio

Sin-Chung Chang and Philip C.E. Jorgenson

Glenn Research Center, Cleveland, Ohio

Prepared for the

First International Conference on Computational Fluid Dynamics sponsored by the Kyoto Institute of Technology

Kyoto, Japan, July 10-14, 2000

National Aeronautics and

Space Administration

Glenn Research Center 
Available from

NASA Center for Aerospace Information

7121 Standard Drive

Hanover, MD 21076

Price Code: A03

National Technical Information Service 5285 Port Royal Road Springfield, VA 22100 Price Code: A03

Available electronically at http://gltrs.grc.nasa.gov/GLTRS 


\title{
Computation of Feedback Aeroacoustic System by the CE/SE Method
}

\author{
Ching Y. Loh and Xiao Y. Wang \\ Taitech Inc. \\ Cleveland, Ohio 44135 \\ Sin-Chung Chang and Philip C.E. Jorgenson \\ National Aeronautics and Space Administration \\ Glenn Research Center \\ Cleveland, Ohio 44135
}

It is well known that due to vortex shedding in high speed flow over cutouts, cavities, and gaps, intense noise may be generated. Strong tonal oscillations occur in a feedback cycle in which the vortices shed from the upstream edge of the cavity convect downstream and impinge on the cavity lip, generating acoustic waves that propagate upstream to excite new vortices. Numerical simulation of such a complicated process requires a scheme that can : (a) resolve acoustic waves with low dispersion and numerical dissipation, (b) handle nonlinear and discontinuous waves (e.g. shocks), and (c) have an effective (near field) non-reflecting boundary condition (NRBC). The new space time conservation element and solution element method, or $\mathrm{CE} / \mathrm{SE}$ for short, is a numerical method that meets the above requirements [1-4]. A detailed description of the 2-D CE/SE Euler scheme can be found in $[1,2]$, only a brief sketch is given here.

\section{The 2-D CE/SE Euler Scheme}

Consider a dimensionless conservation form of the 2-D unsteady Euler equations:

$$
\mathbf{U}_{t}+\mathrm{F}_{x}+\mathrm{G}_{y}=0
$$

where the conservative flow variable vector $\mathbf{U}$ and the flux vectors, $\mathbf{F}$ and $\mathbf{G}$, are given in the usual way. In contrast to other schemes, $U$ and its spatial derivatives $\mathbf{U}_{\mathbf{x}}$ and $\mathbf{U}_{\mathbf{y}}$ are considered as unknowns. Also, the fluxes $\mathbf{F}$ and $\mathbf{G}$ are conveniently written in terms of the components of $U$. The integral form of Eq. (1) in the space-time 3-D Euclidean Space $E_{3}$ is to be solved:

$$
\oint_{S(V)} \mathbf{H}_{\mathbf{m}} \cdot \mathrm{d} \mathbf{S}=\mathbf{0}, \quad \mathbf{m}=1,2,3,4
$$

where $S(V)$ denotes the surface around a volume $V$ in $E_{3}$ and $\mathbf{H}_{\mathbf{m}}=\left(\mathbf{F}_{\mathbf{m}}, \mathbf{G}_{\mathbf{m}}, \mathbf{U}_{\mathbf{m}}\right)$. The time $t$ coordinate points in the direction out from the paper surface. The $\mathrm{CE} / \mathrm{SE}$ method is naturally adapted to an unstructured grid. The unstructured version of the $\mathrm{CE} / \mathrm{SE}$ scheme can be briefly depicted by Fig. 1. Here, $D, E, F$ are the triangle centers where the flow data at the previous time step are given. In the space-time $E_{3}$ space, (2) is applied to the hexagon cylinder $A D B E C F$. U at the hexagon center at the new time level is first evaluated and then by Taylor expansion, $\mathrm{U}$ at the center $O$ of triangle $A B C$ can be obtained. Surface fluxes along 
the line segment planes $A D, D B, B E, E C, C F, F A$ (called solution elements or SE's) can be obtained again by Taylor expansions from the 3 centers $D, E$, and $F$. In the process, (2) is applied to 3 quadrilateral cylinders $O A D B, O B E C$ and $O C F A$, which are termed conservation elements ( $C E^{\prime} s$ ).

In the CE/SE scheme, the above flux conservation relation (2) in space-time is the only mechanism that transfers information between node points. The conservation element $C E$ is the finite volume to which (2) is to be applied. Discontinuities are allowed to occur in the interior of a conservation element. A solution element $S E$ associated with a grid node (e.g., $D, E, F$ in Fig. 1) is here a set of interface planes in $E_{3}$ that passes through this node (e.g. $D A, D B, E B, E C$, etc. ). The solution variables $\mathbf{U}, \mathbf{U}_{\mathbf{x}}$, and $\mathbf{U}_{\mathbf{y}}$ are calculated at this node. Within a given solution element $S E(j, n)$, where $j, n$ are the node index, and time step respectively, the flow variables are not only considered continuous but are also approximated by linear Taylor expansions. Each $S(C E)$ is made up by surface segments belonging to two neighboring $S E$ 's. The number of equations derived from these flux conservation laws matches the number of unknowns (here 12 scalar unknowns). All the unknowns are solved for based on these relations. No extrapolations (interpolations) across a stencil of cells are needed or allowed.

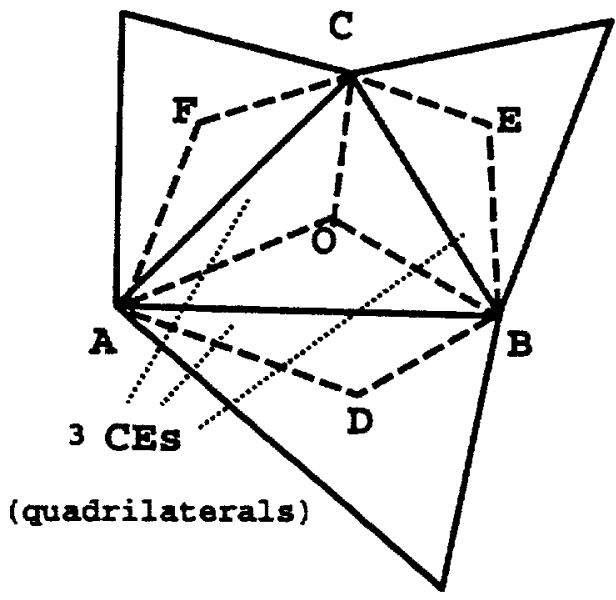

Fig. 1: basic CE/SE grid structure
A
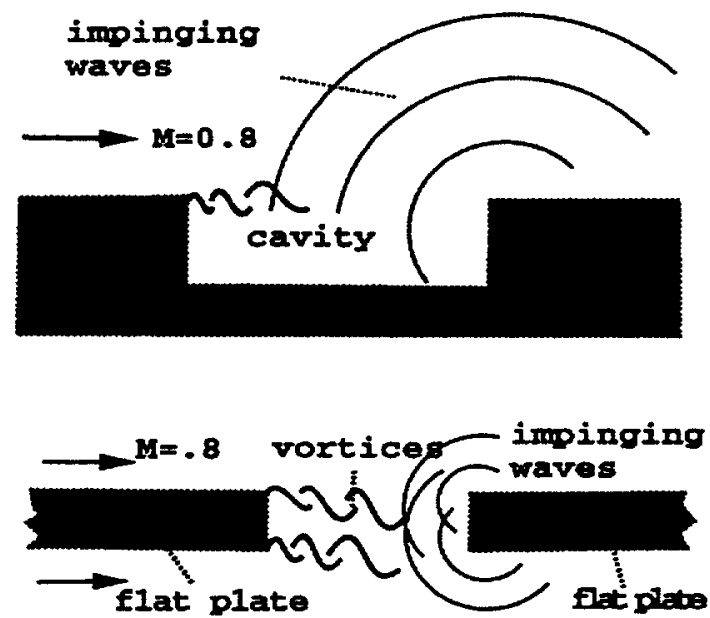

Fig. 2: sketch of (A) cavity noise,

For full details of the implementation of the 2-D CE/SE Euler method, leading to the $a, a-\epsilon$ and weighted $a-\epsilon$ schemes, the reader is referred to [3]. The weighted $a-\epsilon$ scheme is used here. $\epsilon$ denotes an adjustable parameter that controls the numerical dissipation, and the weighted scheme is intended for cases where discontinuities may be present in the inviscid flow field. 


\section{2 the CE/SE Non-Reflecting Boundary Conditions (NRBC)}

In the CE/SE scheme, the idea of characteristics stemming from differential equation theory does not properly apply, since we are solving integral equations instead of differential equations. Rather, the following basic criterion is adopted: In a $C E$ located at the numerical domain boundary, a non-reflecting boundary condition is equivalent to letting the incoming flux from the interior domain to the boundary CE smoothly exit to the exterior of the domain.

As a matter of fact, the 2-D non-reflecting boundary condition has been proven successful even at the near field boundary. There are various versions of the NRBC. The following are the typical ones employed in our computations. For a grid node $(j, n)$ lying at the domain boundary, the first one, labeled type I, requires that $\left(\mathbf{U}_{\mathbf{x}}\right)_{\mathbf{j}}^{\mathbf{n}}=\left(\mathbf{U}_{\mathbf{y}}\right)_{\mathbf{j}}^{\mathbf{n}}=\mathbf{0}$, while $\mathbf{U}_{\mathbf{j}}^{\mathbf{n}}$ is kept fixed at the initially given steady boundary value. Type II, for cases where there is a substantial gradient in, say, the y direction, requires that $\left(\mathbf{U}_{\mathbf{x}}\right)_{\mathbf{j}^{\mathbf{n}}}^{\mathbf{n}}=\mathbf{0}, \mathbf{U}_{\mathbf{j}}^{\mathbf{n}}=\mathbf{U}_{\mathbf{j}^{\prime}}^{\mathbf{n}-\mathbf{1}}, \quad\left(\mathbf{U}_{\mathbf{y}}\right)_{\mathbf{j}}^{\mathbf{n}}=\left(\mathbf{U}_{\mathbf{y}}\right)_{\mathbf{j}^{\prime}}^{\mathbf{n}-\mathbf{1}}$, where $j^{\prime}$ denotes the nearest interior node to the boundary node $j$. The proposed non-reflecting boundary conditions above are all simple, truly multi-dimensional and quite effective. Our experiences show that, in general, the reflection amounts to about $1 \%$ or even lower.

\section{Numerical results for the gap noise problem}

As typical aeroacoustic feedback systems, Figure 2 illustrates the geometric configurations which model the gap and cavity noise problems. Both produce sustainable feedback cycle oscillations as a result of vortex shedding (receptivity) at the upstream edge and acoustic feedback.

Figure 3 shows snapshots of the generation and pairing of vortices and the generation of (nonlinear) acoustic waves by vortex- flat plate impingement in the gap noise problem. The noise generated between the rudder and the stablizer of an aeroplane is a typical example of gap noise. In the current computation: there are 50720 triangle elements for the unstructured mesh in the computational domain. These triangles are actually obtained by dividing a rectangular structured mesh cell into 4 pieces (e.g. Figure 4 ). The rectangular cell keeps a uniform size of $\Delta x=0.04$ and $\Delta y=0.01$ around the area of the gap but grows larger near the boundaries. The mean flow follows the $x$-direction with Mach number $M=0.8$. Fig. 3 is taken after 10000 time steps are run. At the inlet, the $M=0.8$ flow is imposed. At the top and bottom the Type I NRBC is used while at the outflow, the Type II NRBC is specified. The domain shown in Fig. 3 is exactly the the computational domain, no buffer zone is used but still, the $\mathrm{CE} / \mathrm{SE} \mathrm{NRBC}$ is very effective.

\section{Numerical results for the subsonic cavity noise problem}

In the second problem, a $M=0.8$ subsonic flow passes over a cavity of aspect ratio 6.5. As in the first problem, tonal oscillations occur in a feedback cycle in 


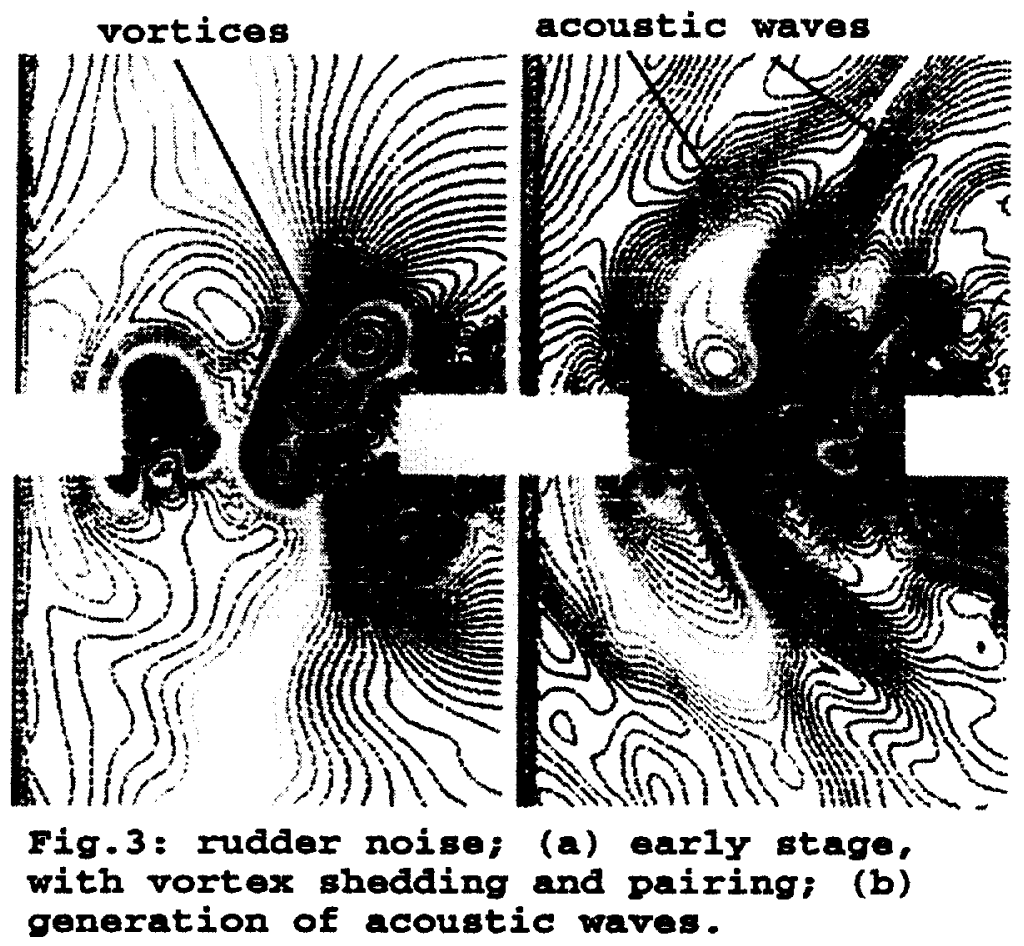

which the vortices shed from the upstream lip of the cavity convect downstream and impinge on the other lip, generating acoustic waves that in turn propagate upstream to excite new vortices.

In the computational domain, 42000 triangular elements are used in the unstructured grid, which is again made from structured rectangular cells (Figure 4). Figure 5 depicts with isobars where the acoustic waves are generated and propagate in a series of snapshots (1-12) in the near field of the cavity. Each snapshot is 3.6 (720 steps) unit apart in time. The boundary conditions are similar to the first example. No visible reflections are observed at the non-reflecting boundaries. At the inflow boundary, upstream propagating waves are well absorbed within a few (4-6) cells, without contaminating the interior domain. From an animation of the solution, the near field acoustic wave structure is quite complicated.

\section{Concluding Remarks}

Two typical vortex induced, self-excited oscillation aeroacoustic systems are successfully simulated. Through these 'difficult' problems, the capability of the new CE/SE scheme is demonstrated. Specifically,

1. the (2nd order) $\mathrm{CE} / \mathrm{SE}$ scheme is robust, efficient and yields high resolution, low dispersion results similar to those of higher-order schemes; 


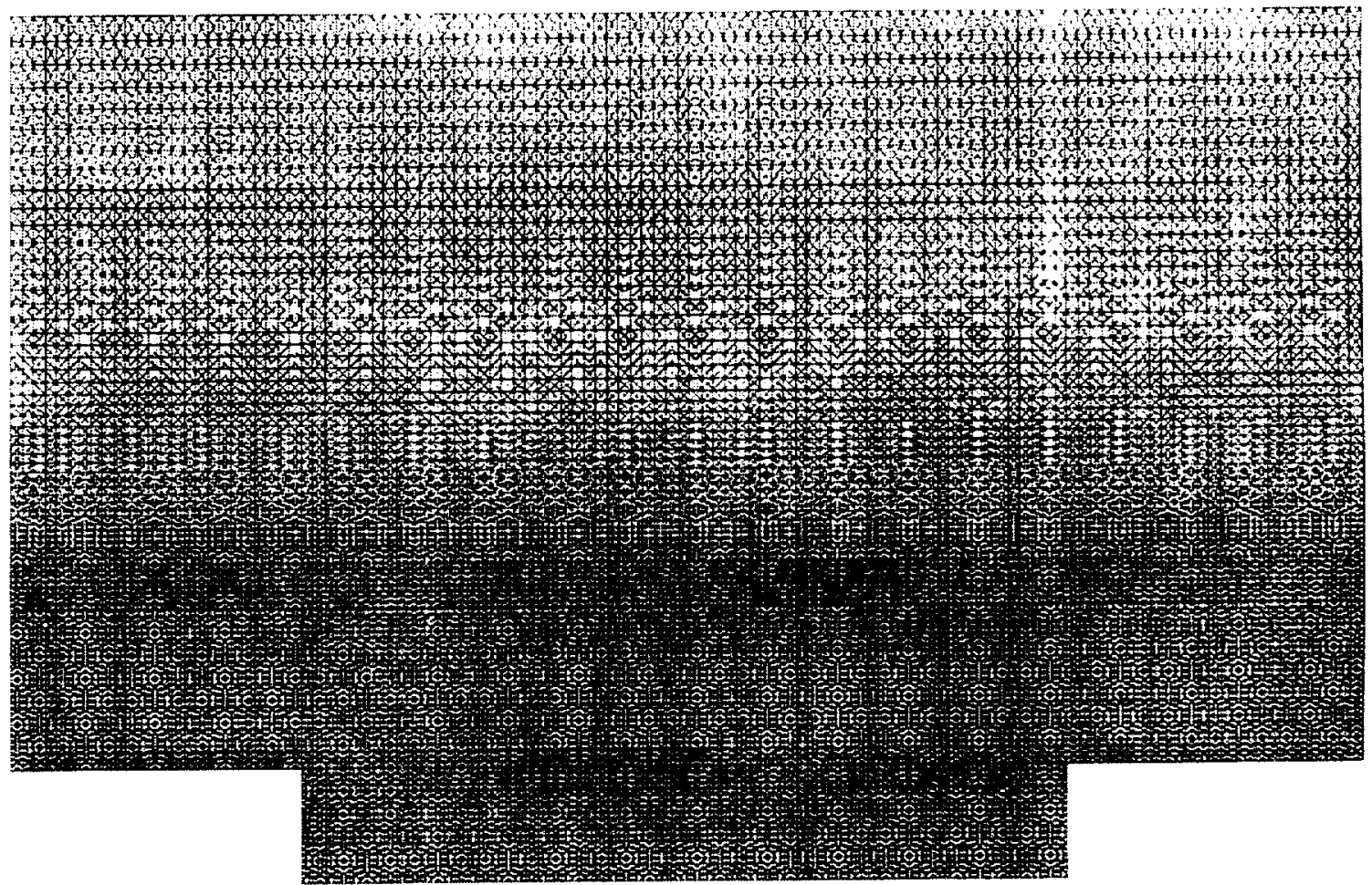

Fig. 4 Unstructured grid used in the cavity noise problem, totally 42000 trianglular elements.

2. the novel non-reflecting boundary conditions based on flux balance is simple, genuinely multi-dimensional, and easy to implement.

\section{References}

[1] Chang, S. C., "The Method of Space-Time Conservation Element and Solution Element-A New Approach for Solving the Navier-Stokes and Euler Equations," Journal of Computational Physics. v. 119, 295-324 (1995).

[2] Chang, S.-C., Wang, X.-Y. and Chow, C.-Y., "The Space-Time Conservation Element and Solution Element Method: A New High Resolution and Genuinely Multidimensional Paradigm for Solving Conservation Laws ", J. Comp. Phys. v.156, 89-136 (1999).

[3] Loh, Ching Y., Hultgren, Lennart S. and Sin-Chung Chang, "Computing Waves in Compressible Flow Using the Space-Time Conservation Element Solution Element Method," ALAA Paper 98-0369 (1998).

[4] Loh, C. Y., Hultgren, L. S., Chang, S.-C. and Jorgenson, P. C. E., "Vortex Dynamics Simulation in Aeroacoustics by the Space-Time Conservation Element Solution Element Method," AIA A Paper 99-0359 (1999). 


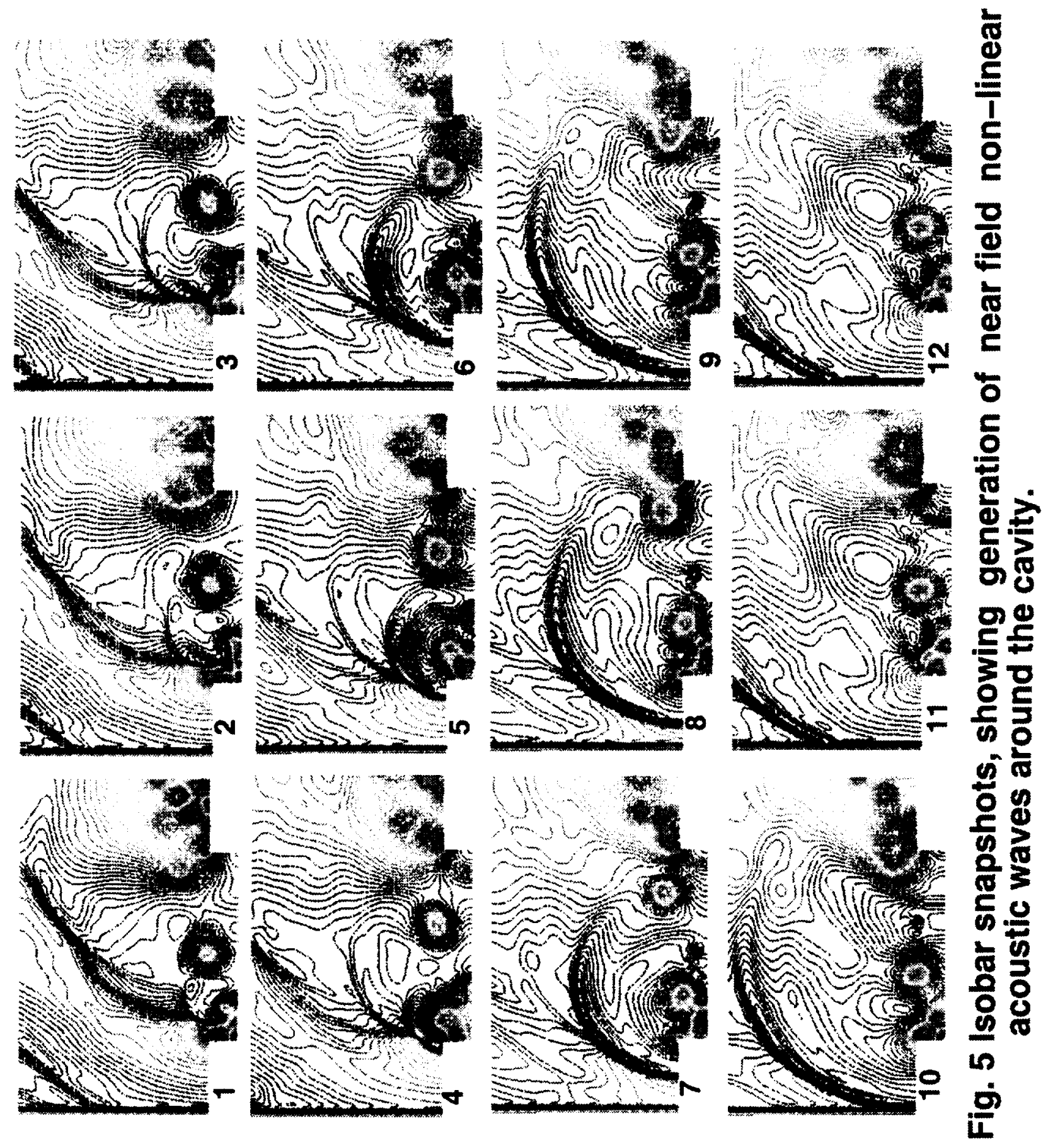


Public reporting burden for this collection of information is estimated to average 1 hour per response, including the time for reviewing instructions, searching existing data sources, collection of intormation including suggestions for reducing and reviewing the collection of hiormation. Sens comments regarding this burden estimate or any other aspect of this Davis Highway, Sute 1204. Arlington, VA 22202-4302, and to the Office of Management and Budget Papenwork Reduction Project (0704-0183), Washington, DC, 215 Jefferson

\begin{tabular}{|l|l|l|}
\hline 1. AGENCY USE ONLY (Leave blank) & 2. REPOAT DATE & 3. REPORT TYPE AND DATES COVERED
\end{tabular}

\section{TITLE AND SUBTITLE}

October 2000

Technical Memorandum

Computation of Feedback Aeroacoustic System by the CE/SE Method

6. AUTHOR(S)

Ching Y. Loh, Xiao Y. Wang, Sin-Chung Chang, and Philip C.E. Jorgenson

7. PERFORMING ORGANIZATION NAME(S) AND ADDRESS(ES)

National Aeronautics and Space Administration

John H. Glenn Research Center at Lewis Field

Cleveland, Ohio 44135-3191

9. SPONSORING/MONITORING AGENCY NAME(S) AND ADDRESS(ES)

National Aeronautics and Space Administration

Washington, DC 20546-0001
WU-523-90-43-00

5. FUNDING NUMBERS

8. PERFORMING ORGANIZATION REPORT NUMBER

E-12475

10. SPONSORING/MONITORING AGENCY REPORT NUMBER

NASA TM-2000-210479

\section{SUPPLEMENTARY NOTES}

Prepared for the First International Conference on Computational Fluid Dynamics sponsored by the Kyoto Institute of Technology, Kyoto, Japan, July 10-14, 2000. Ching Y. Loh and Xiao Y. Wang, Taitech Inc., Cleveland, Ohio 44135; Sin-Chung Chang and Philip C.E. Jorgenson, NASA Glenn Research Center. Responsible person, Philip C.E. Jorgenson, organization code $5880,1-216-433-5386$.

12a. DISTRIBUTION/AVAILABILITY STATEMENT

Unclassified - Unlimited

Subject Categories: 02 and 64
Distribution: Nonstandard

This publication is available from the NASA Center for AeroSpace Information, 1-301-621-0390. 12b. DISTRIBUTION CODE

\section{ABSTRACT (Maximum 200 words)}

It is well known that due to vortex shedding in high speed flow over cutouts, cavities, and gaps, intense noise may be generated. Strong tonal oscillations occur in a feedback cycle in which the vortices shed from the upstream edge of the cavity convect downstream and impinge on the cavity lip, generating acoustic waves that propagate upstream to excite new vortices. Numerical simulation of such a complicated process requires a scheme that can: (a) resolve acoustic waves with low dispersion and numerical dissipation, (b) handle nonlinear and discontinuous waves (e.g. shocks), and (c) have an effective (near field) nonreflecting boundary condition (NRBC). The new space time conservation element and solution element method, or $\mathrm{CE} / \mathrm{SE}$ for short, is a numerical method that meets the above requirements.

\section{SUBJECT TERMS}

Aeroacoustics; CE/SE method

17. SECURITY CLASSIFICATION OF REPORT

Unclassified
18. SECURITY CLASSIFICATION OF THIS PAGE Unclassified
19. SECURITY CLASSIFICATION OF ABSTRACT Unclassified

\section{NUMBER OF PAGES}

16. PRICE CODE

$$
\mathrm{AO} 3
$$

20. LMMITATION OF ABSTRACT


.

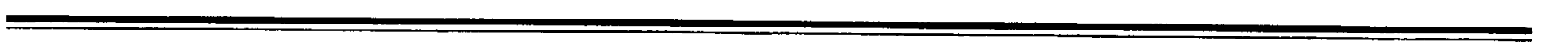

